\title{
Decrease of VLF transmitter signal and Chorus-whistler waves before l'Aquila earthquake occurrence
}

\author{
M. Y. Boudjada ${ }^{1}$, K. Schwingenschuh ${ }^{1}$, R. Döller ${ }^{2}$, A. Rohznoi ${ }^{3}$, M. Parrot ${ }^{4}$, P. F. Biagi ${ }^{5}$, P. H. M. Galopeau ${ }^{6}$,

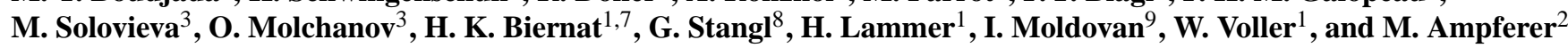 \\ ${ }^{1}$ Space Research Institute, Austrian Academy of Sciences, Graz, Austria \\ ${ }^{2}$ Institute of Physics, Department of Geophysics, Astronomy and Meteorologie, KF University Graz, Graz, Austria \\ ${ }^{3}$ Institute of the Earth Physics, Russian Academy of Sciences, Moscow, Russia \\ ${ }^{4}$ Laboratoire de Physique et Chimie de l'Environnement et de l'Espace, Orléans, France \\ ${ }^{5}$ Department of Physics, University of Bari, Bari, Italy \\ ${ }^{6}$ Laboratoire Atmosphères, Milieux, Observations Spatiales, CNRS, UVSQ, Guyancourt, France \\ ${ }^{7}$ Institute of Physics, Department of Theoretical Physics, KF University Graz, Graz, Austria \\ ${ }^{8}$ Federal Office of Metrology and Surveying, Vienna, Austria \\ ${ }^{9}$ National Institute of Research and Development for Earth Physics, Bucharest, Rumania
}

Received: 9 October 2009 - Revised: 28 January 2010 - Accepted: 9 June 2010 - Published: 9 July 2010

\begin{abstract}
We investigate the VLF emissions observed by the Instrument Champ Electrique (ICE) experiment onboard the DEMETER micro-satellite. We analyze intensity level variation 10 days before and after the occurrence of l'Aquila earthquake (EQ). We found a clear decrease of the VLF received signal related to ionospheric whistler mode (mainly Chorus emission) and to signal transmitted by the DFY VLF station in Germany, few days (more than one week) before the earthquake. The VLF power spectral density decreases of more than two orders of magnitude until the EQ, and it recovers to normal levels just after the EQ occurrence. The geomagnetic activity is principally weak four days before EQ and increases again one day before l'Aquila seismic event. Our results are discussed in the frame of short- and longterms earthquakes prediction focusing on the crucial role of the magnetic field of the Earth.
\end{abstract}

\section{Introduction}

Since the pioneer papers of Gokhberg et al. (1982) and Warwick et al. (1982) much work has been done to detect and analyze the presence of electromagnetic phenomena associated with earthquakes (hereafter EQs). Several papers have shown anomalous increases in the intensity of electromagnetic re-

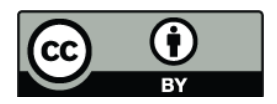

Correspondence to: M. Y. Boudjada (mohammed.boudjada@oeaw.ac.at) ceived signal during the period just prior to earthquakes. A recent book of Molchanov and Hayakawa (2008) reviews the main investigations and results in the frame of the so-called "seismo-electromagnetic and related phenomena".

\subsection{Ground-based investigations}

One important aspect of these seismic research is the analysis of the ionospheric disturbances observed principally over the seismic regions. EQ precursory signatures appear not only in the lithosphere, but also in the atmosphere and ionosphere. Investigations are based on the analysis of radio signals, recorded by ground-based stations, associated to VLF (3-30 kHz) and LF (30-300 kHz) frequency bands.

The original idea have been proposed by Gokhberg et al. (1989) and Gufeld et al. (1992). The authors suggested the use of anomalies in the Earth-ionosphere waveguide propagation of VLF navigation signals for a shortterm earthquake prediction. The principal studies showed anomalies (amplitude and/or phase) in the radio signal few days (from 3 days to 10 days) before the occurrence of large earthquakes with a magnitude more than 5.5 in the case of VLF (Hayakawa and Sato, 1994; Hayakawa et al., 1996; Molchanov and Hayakawa, 1998; Rozhnoi et al., 2004; Yamauchi et al., 2007) and LF bands (Biagi and Hayakawa, 2002; Biagi et al., 2007). The conclusion of these authors are that the ionospheric D- and E-layers are affected by EQs occurrence. 


\subsection{Space-borne studies}

The analysis of the upper ionospheric layer (F-layer) confirms the ground-based observations. This has been reported first by Gokhberg et al. (1983), and followed later on by several authors using mainly electric and magnetic field measurements onboard satellites combined to new processing technics (Parrot et al., 1993; Pulinets et al., 1994). Statistical approach based on the use of more than 3000 satellite orbits of INTERCOSMOS-24 shows a reliable correlation between the global distribution of seismic activity and ion density variations (Hayakawa et al., 2000).

Two main physical interpretations have been considered for the ionospheric pre-seismic observations. The first is related with the effect on ionosphere of acoustic gravity waves generated in the earthquake region (Pulinets and Boyarchuk, 2004), and the second is associated to the lithospheric electric fields penetrating from the earthquake zone into the ionosphere where the atmospheric conductivity is considered to be a key physical parameter (Denisenko et al., 2008). The GPS technic have provided a new approach to detect the ionospheric disturbances associated to seismic activity (Liu et al., 2001) instead of, or as complement, to the classic space ionosonde technic (Pulinets et al., 1998).

\subsection{Analysis of sub-ionospheric signals using DEMETER observations}

DEMETER space observations provides a very interesting opportunity to investigate and to study earthquakes electromagnetic precursors. Recently, statistical investigations, using a larger set of data (more than 3.5 years of measurements) confirm the existence of a very small but statistically significant decrease of the electromagnetic wave intensity few hours (between $0 \mathrm{~h}$ and $4 \mathrm{~h}$ ) before the time of the main shock and this at a frequency around $1.7 \mathrm{kHz}$ (Němec et al., 2009).

Moreover new emphasis has been given to the analysis of the ground transmitter signal as detected by DEMETER micro-satellite above seismic regions. This has first been reported by Molchanov et al. (2006) who found a drop of the subionospheric transmitter signals few days before EQs occurrence. This results have been confirmed by ground-based and/or space observations (Rozhnoi et al., 2007, 2009; Muto et al., 2008; Boudjada et al., 2008). These studies considered principally EQs which occurred in Europe (23-24 November and 5 December 2004), in Sumatra - Indonesia - (end of the year 2004), in Kamchatka (Russia) and Japan region (November and December 2004; July, August and September 2005). The applied method consists to estimate the signal to noise ratio (SNR) using the following relation:

$\mathrm{SNR}=2 A\left(F_{0}\right) /\left[A\left(F_{+}\right)+A\left(F_{-}\right)\right]$

where $A\left(F_{0}\right)$ is the amplitude spectrum density in the frequency band including the transmitter frequency $F_{0}$ and $A\left(F_{ \pm}\right)$are the values outside of the signal band. Another and different method based mainly on the processing of the recorded dynamic spectrum, for each half-orbit, leads to estimate the maximum of intensity level through the observed channel frequencies of ICE experiment (Boudjada et al., 2008). Both methods show a decrease or a drop the transmitter signal over seismic regions.

A tentative interpretation has been given by Molchanov et al. (2006) where authors consider that the initial agent is an up-going energy flux of atmospheric gravity waves (AGW). The penetration of AGW waves into the ionosphere leads to modification of the natural (background) ionospheric turbulence (Molchanov et al., 2004; Hobara et al., 2005). In this model the ground-based VLF station signals is scattered in the ionospheric turbulence region above the earthquake preparatory zone. The decrease of the intensity is mainly due to the scattering of the VLF transmitter signal.

In this paper we report on VLF emissions of l'Aquila EQ taking into consideration the transmitter signal emitted by DFY-Germany $\left(\right.$ Longitude $=13^{\circ} \mathrm{E}$, Latitude $\left.=52.5^{\circ} \mathrm{N}\right)$ at a frequency of $16.56 \mathrm{kHz}$. In Sect. 2 we first describe the ICE experiment characteristics and the way the data are processed. Then we consider the variation of the VLF intensity levels for the natural and artificial signals recorded 10 days before and after l'Aquila EQ. In Sect. 3 we discuss our main results in particular the accuracy measurements, the latitudinal effect and the role of magnetic field measurements. In Sect. 4 we summarize our main results.

\section{Investigation of l'Aquila earthquake}

\subsection{Instrument Champ Electrique (ICE) experiment}

We use space observations provided by DEMETER microsatellite to investigate l'Aquila earthquakes. The ICE experiment (Berthelier et al., 2006) performs a continuous survey of the electric field over a wide frequency range. This experiment consists of 4 spherical sensors with embedded preamplifier electronics mounted on the ends of 4 booms. The electric field component is determined along the axis defined by two sensors. Any pair of sensors among the four can be used for this objective which enables the 3 components of the $\mathrm{DC}$ and $\mathrm{AC}$ vector electric field to be measured.

There are two modes of operation, a survey mode to record low bit rate data all around the Earth at invariant latitudes less than $\pm 65^{\circ}$, and a burst mode to record high bit rate data above seismic regions. We use the survey mode in our study. The data are stored in a large onboard memory which is downloaded two times per day when the satellite is above Toulouse (Toulouse), the location of the Operation Center. Then, the data is sent to the DEMETER Mission Center in Orléans (France) where data processing is performed (Lagoutte et al., 2006). 

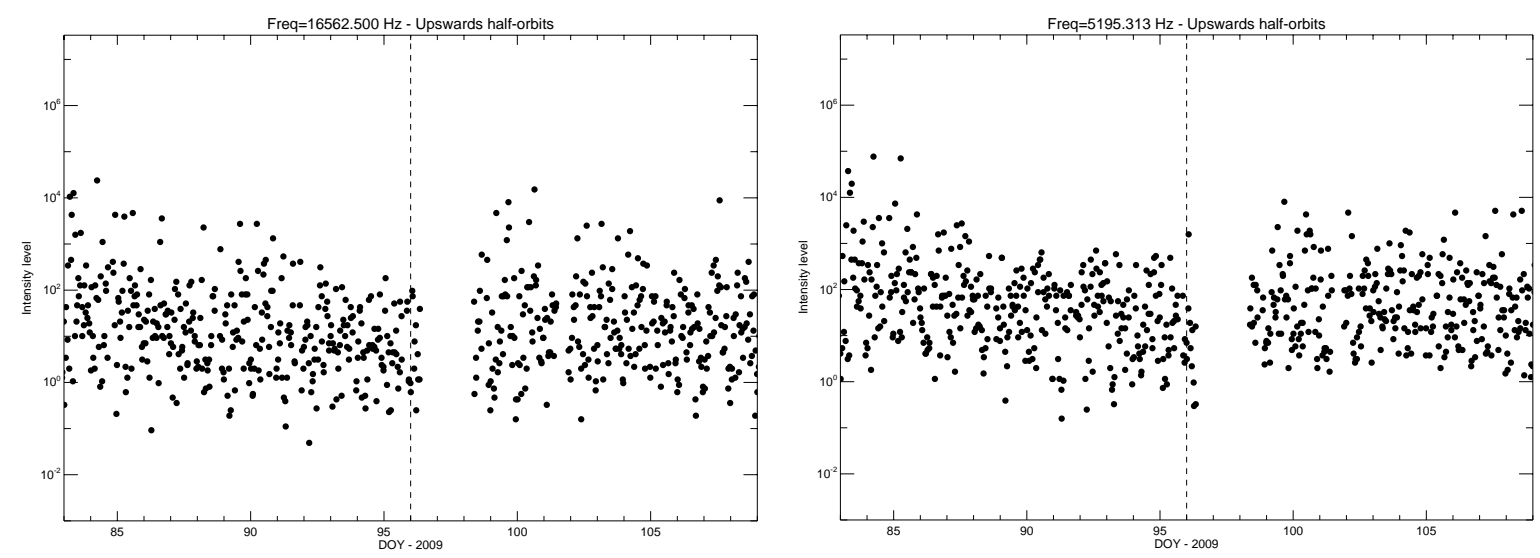

Fig. 1. Variation of the intensity level (expressed in $\mathrm{mV}^{2} \mathrm{~m}^{-2} \mathrm{~Hz}^{-1}$ ) time series versus the day of the year 2009 (from $24 \mathrm{March}$ to 19 April 2009). The left and right figures correspond to the intensity variation at $16652.5 \mathrm{~Hz}$ (the closest frequency to the German transmitter signal $16560 \mathrm{~Hz}$ ) and $5195.313 \mathrm{~Hz}$, respectively. The EQ date corresponds to 6 April 2009, and is indicated by a dashed vertical line.

In the case of the ICE experiment four frequency bands have been defined, DC/ULF [0-15 Hz], ELF [15 Hz-1 kHz], VLF $[15 \mathrm{~Hz}-17.4 \mathrm{kHz}]$ and HF $[10 \mathrm{kHz}-3.175 \mathrm{MHz}]$. The power spectrum is computed with frequency and temporal resolutions that depend on the spacecraft and ICE modes of operation. In the burst mode the power spectrum is stored with a $19.53 \mathrm{~Hz}$ frequency resolution and averaged over $2.048 \mathrm{~s}$ (Berthelier et al., 2006).

\subsection{Data processing and method of investigation}

The ICE experiment provides a survey observations from ULF to HF frequencies for each half-orbit. The survey consists of a dynamic spectrum showing the intensity level variation versus the frequency range and the observation time. Each dynamic spectrum is obtained of 980 sequential spectra, each consisting of 1024 frequency channels. The high spectral resolution of the experiment (size pixel is $2.048 \mathrm{~s} \times 19.51 \mathrm{~Hz}$ ) leads to record ionospheric components like the hiss, the chorus, the whistlers, and the transmitter artificial signals.

In our analysis we apply the spectral method described in Boudjada et al. (2008). It is based on the study of the variation of the intensity level of VLF emissions as recorded by ICE experiment during each half-orbit. We define an "activity index" which quantifies and describes, for each half-orbit, the maximum intensity level on each channel before and after the geographic equator. It is clearly shown (see Fig. 2b of Boudjada et al., 2008) that the so-called "maximum-curve" gives more spectral features about the ionospheric emissions, than the three other options, i.e. "average", "medium" and "minimum" curves. The spectral envelope (i.e. "maximacurve") is used hereafter to estimate the intensity level variations.

\subsection{Earthquake of 6 April $2009(M=5.6)$}

Figure 1 shows the intensity variation of the natural ionospheric emission (right-side of Fig. 1) and transmitter signal (left-side in Fig. 1) as recorded by DEMETER/ICE experiment. Two frequencies have been selected $16562.500 \mathrm{~Hz}$ and $5195.313 \mathrm{~Hz}$ which correspond to the closest transmitter frequency and to the whistler mode frequency (mainly in the chorus frequency range), respectively. We consider a time period of 26 days centered on 6 April 2009, date of the l'Aquila earthquake. A gap of about 2 days (mainly on 6 and 7 April) occurs in the data few hours after l'Aquila EQ.

The amplitude decrease of the signal is clearly seen in Fig. 1, in both cases, for transmitter and ionospheric signals. One could consider the envelope associated to the maxima intensities observed before the EQ occurrence. Table 1 lists the maximum of intensity level observed 10 days before l'Aquila seismic event. In the case of the transmitter signal one note a clear decrease from $3 \times 10^{4} \mathrm{mV}^{2} \mathrm{~m}^{-2} \mathrm{~Hz}^{-1}$ (DOY 84 ) to $8 \times 10^{1} \mathrm{mV}^{2} \mathrm{~m}^{-2} \mathrm{~Hz}^{-1}$ (DOY 94), which is more than two orders of magnitude (see Fig. 1, left panel).

Similar behaviors are found for the ionospheric natural emissions where the decrease, or the drop, is more pronounced than in the case of the transmitter signal. This is shown in Fig. 1 (right-panel) and corresponding maxima recorded before the seismic events are reported in Table 1. It is very difficult to spot the increase of the VLF signal just after the EQ because of the limited number of measurements and the gap presence. However one notes that the VLF signal is recovered at least two days after the EQ. The geomagnetic activity is found to progressively decrease up to two days before l'Aquila EQ, afterward the daily sum Kp-index increases again as shown in Fig. 2 (left-panel). 

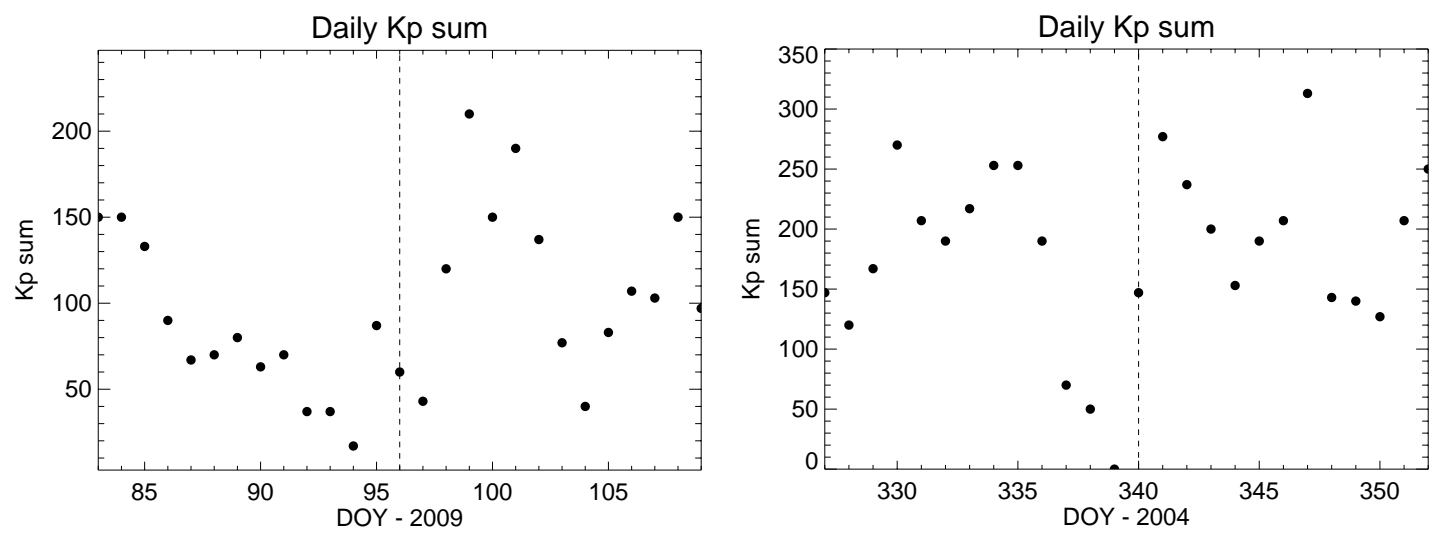

Fig. 2. Variation of the daily sum Kp-index 10 days before and after seismic events which occurred on 6 April 2009 (left panel) and 5 December 2004 (right panel). The EQ dates are indicated by dashed vertical lines.
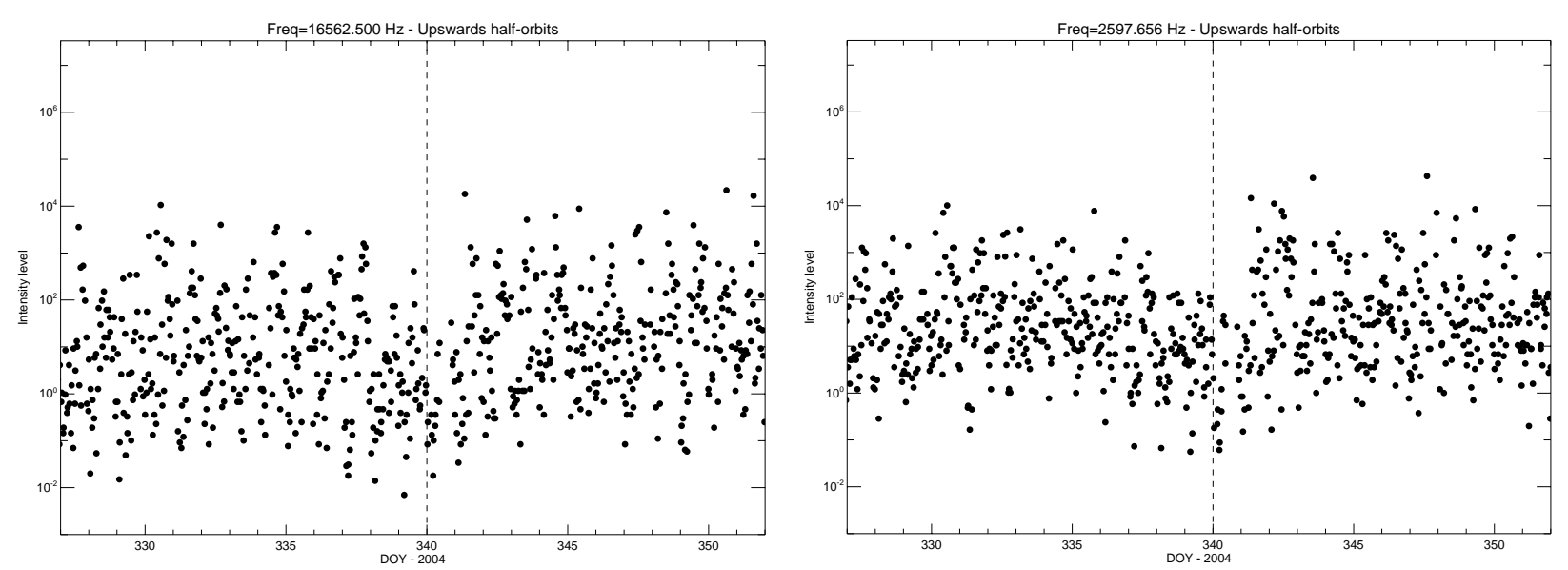

Fig. 3. Variation of the intensity level (expressed in $\mathrm{mV}^{2} \mathrm{~m}^{-2} \mathrm{~Hz}^{-1}$ ) versus the day of the year 2004 (from 22 November to $17 \mathrm{December}$ 2004). The left and right figures correspond to the intensity variation at $16652.5 \mathrm{~Hz}$ (the closest frequency to the German transmitter signal $16560 \mathrm{~Hz}$ ) and $2597.656 \mathrm{~Hz}$, respectively. The EQ date corresponds to 5 December 2004, and is indicated by a dashed vertical line.

\subsection{European earthquake of 5 December $2004(M=5.6)$}

It is interesting to combine the features of the l'Aquila EQ to another European seismic event that occurred on 5 December 2004. Figures 3 shows the VLF intensity level variation over the EQ region. Table 1 lists the intensity level variations for the same transmitter in Germany and for a given VLF ionospheric emission observed a frequency of about $2.6 \mathrm{kHz}$. In the case of this event, the clear decrease only appeared a few days (5 days) before EQ occurrence much earlier (10 days) for l'Aquila event (see Figs. 1 and 3). With regard to the geomagnetic activity one note that, in both cases, the daily Kp sum is very low, less than 40 as shown in Fig.2 (right panel).

\section{Discussion}

In the frame of the l'Aquila EQ we analyzed the variation of the levels of VLF ionospheric emissions and transmitter signals as recorded by the ICE experiment onboard DEMETER micro-satellite. The decrease of the power density level is found to be similar in both cases, i.e. for natural and the artificial signals. In the following we discuss first the accuracy measurements, the latitudinal effect and the role of the Earth's magnetic field.

\subsection{Accuracy of VLF intensity measurements}

It is possible to check the temporal variation of the VLF intensity for a period longer than one month, and to provide an estimation on the measurements. Figure 4 shows the variation of the VLF intensity versus the day of the year 2009. The period of investigation covers four months, i.e. 
Table 1. Intensity level variations for transmitter signal $(f=16652.5 \mathrm{~Hz})$, and natural VLF ionospheric emissions $(f=5195.313 \mathrm{~Hz})$ before l'Aquila EQ occurrence.

\begin{tabular}{lcccccccccccccc}
\hline Freq. (Hz) & Figure & Year & $I$ & DOY & $I$ & DOY & $I$ & DOY & $I$ & DOY & $I$ & DOY & $I$ & DOY \\
\hline 16652.5 & 1 & 2009 & $3 \times 10^{4}$ & 084 & $7 \times 10^{3}$ & 086 & $3 \times 10^{3}$ & 088 & $5 \times 10^{3}$ & 090 & $5 \times 10^{2}$ & 092 & $8 \times 10^{1}$ & 094 \\
5195.313 & 1 & 2009 & $8 \times 10^{4}$ & 084 & $3 \times 10^{3}$ & 086 & $7 \times 10^{2}$ & 088 & $8 \times 10^{2}$ & 090 & $9 \times 10^{2}$ & 092 & $9 \times 10^{1}$ & 094 \\
16652.5 & 3 & 2004 & $1 \times 10^{2}$ & 328 & $1 \times 10^{4}$ & 330 & $6 \times 10^{3}$ & 332 & $5 \times 10^{3}$ & 334 & $9 \times 10^{2}$ & 336 & $1 \times 10^{2}$ & 338 \\
2597.656 & 3 & 2004 & $7 \times 10^{3}$ & 328 & $1 \times 10^{4}$ & 330 & $5 \times 10^{3}$ & 332 & $2 \times 10^{3}$ & 334 & $3 \times 10^{3}$ & 336 & $1 \times 10^{2}$ & 338 \\
\hline
\end{tabular}
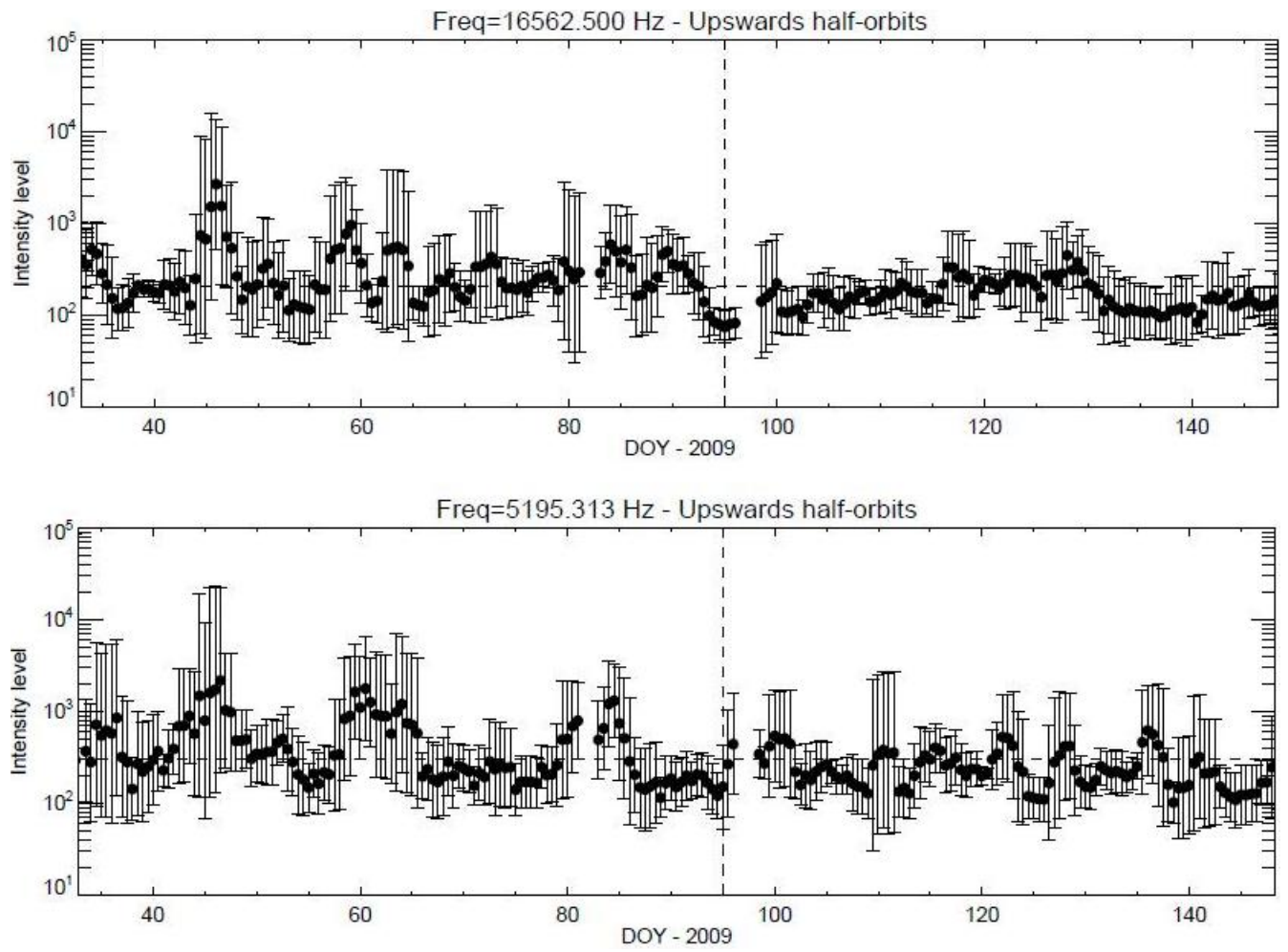

Fig. 4. Variation of the averaged VLF intensity level versus the day of the year 2009 (from 1 February to 28 May). The vertical and horizontal dashed lines indicate respectively the day of EQ occurrence and the mean VLF intensity (over the investigated period of about 4 months).

February, March, April, and Mai 2009. We neglect, first, all points of Fig. 1 where the intensity levels are smaller than $50 \mathrm{mV}^{2} \mathrm{~m}^{-2} \mathrm{~Hz}^{-1}$. The aim is to remove points with low intensity level which can be considered as noise backgrounds. Afterward, the use of the interpolation method leads to compute the VLF intensity variation for each half day. In the third step, we compute the VLF intensity mean and the corresponding standard deviation derived from a sample population of 5 elements around the interpolated point.

The VLF transmitter intensity (see upper panel in Fig. 4) has a level, on average, higher than $5 \times 10 \mathrm{mV}^{2} \mathrm{~m}^{-2} \mathrm{~Hz}^{-1}$, and maxima of about $10^{2} \mathrm{mV}^{2} \mathrm{~m}^{-2} \mathrm{~Hz}^{-1}$ in the time interval from the beginning of February to the middle of March 2009. Afterwards, one note a progressive decrease of VLF intensity with a minimum observed on the day of the EQ. A particular decrease of about one order of magnitude appears seven days before the seismic event. Later the transmitter signal increases but never reach values similar to those observed in February and March.

Similar behavior is observed in the VLF whistler intensity as it is shown in Fig. 4 (lower panel). The level of intensity is particularly important in February, and starts to decrease after the middle of March 2009. During several days (at least 10 days) before EQ, the VLF whistler signal is found to be low. A clear jump in the intensity level is observed one day after the earthquake, and stay variable until the end of May 2009.

Combining Figs. 1 and 4, on can conclude that transmitter VLF signal, like whistler emissions, shows a decrease of the intensity level. The time interval of four months leads to find that other decreases exist. However before (one week) and after (two/three weeks) the earthquake occurrence, the VLF intensity level is low compared to what was observed in February and beginning of March 2009. 

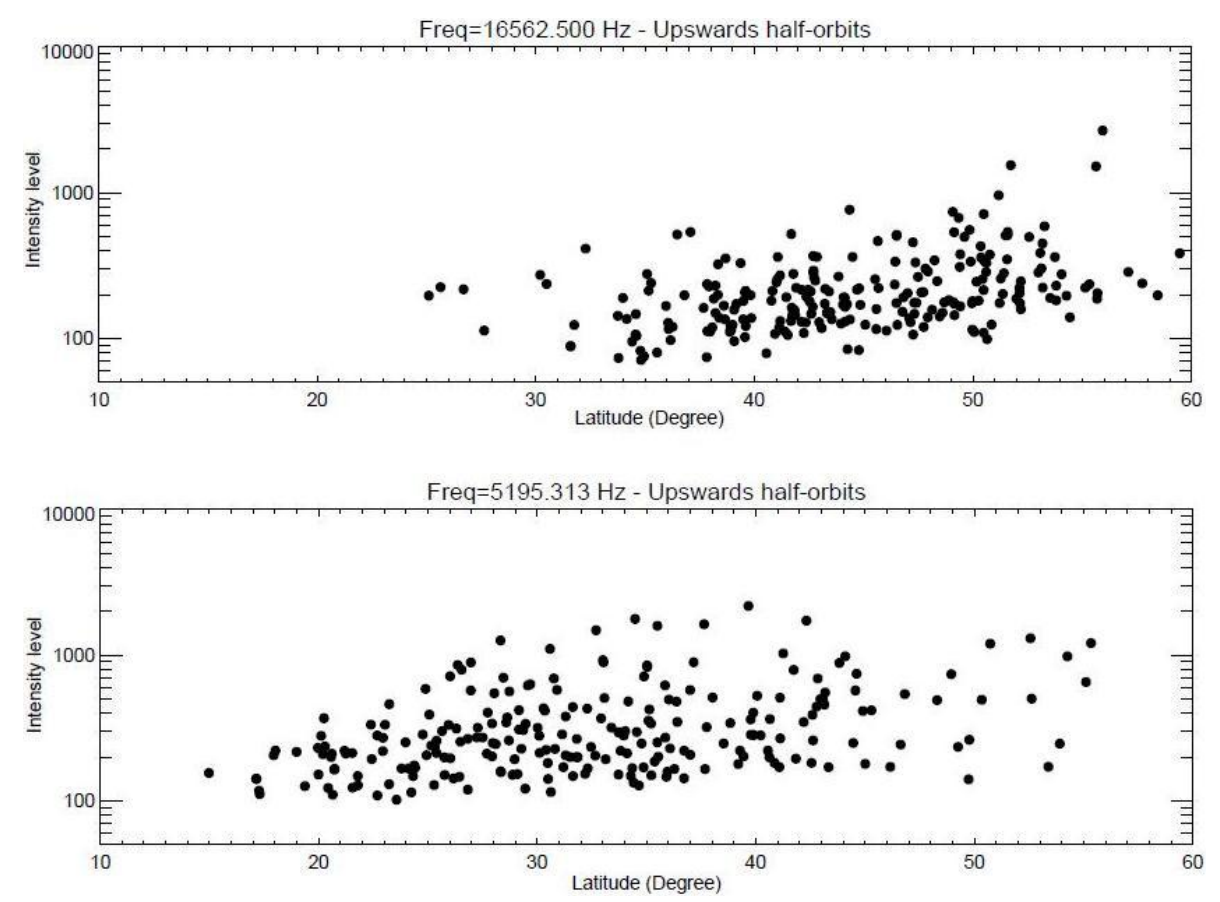

Fig. 5. Variation of the averaged intensity level versus the DEMETER satellite latitudes in the case of the transmitter signal $(f=16562.5 \mathrm{~Hz})$ and the VLF whistler emissions $(f=5195.313)$. The intensity measurement points are similar to those shown in Fig. 4.

\subsection{Latitudinal effect on VLF intensity signal}

It is interesting to study the dependence, or not, of the VLF intensity signals on the satellite latitudes. Figure 5 displays the variation of the VLF intensity level versus the satellite latitudes in the Northern hemisphere where occurred the earthquake. The intensity measurement points are similar to those shown in Fig. 4. For the transmitter signal (upper panel in Fig. 5) maxima values are mainly observed at latitude of about $50^{\circ}$. The enhancement of VLF signal, at such latitudes, is due to the geographic location of the DFY-Germany station $\left(52.5^{\circ} \mathrm{N}\right)$. Also the signal is weak, and sometimes quasi-absent, when the satellite is close to the Earth's equator. This result is in agreement with finding of Molchanov et al. (2006) who reported similar characteristics of the transmitter signal above the VLF ground-station and at the equatorial plan. The whistler VLF emission mainly covers latitude interval between $25^{\circ}$ and $45^{\circ}$. The dependence on latitude is not evident in particular at latitudes smaller than $45^{\circ}$. Above, and around, the seismic region (at latitude of about $40^{\circ}$ ) the VLF whistler emission is not subject to the latitudinal effect. However the auroral influence is observed at latitudes higher than $50^{\circ}$.

\subsection{Earth's magnetic field}

It comes from our analysis that a low Kp-index and a dependence on local time could be considered as key parameters which contribute to the comprehension of the earth- quake generation mechanism(s) at the origin of electromagnetic pre-seismic emissions. The role of the Earth's magnetic field is a crucial element. It mainly originates from dynamo effect related to the Earth's core, before to emerge from the crust. The magnetic field measurements could be considered as a sum of magnetic fields from different sources. The principal sources are the main field and the statistic lithospheric field. However there are regular daily variations fields arising from electrical current system in the ionosphere and magnetosphere regions.

Parameters like $\mathrm{Kp}$ and $\mathrm{Sq}$ are aimed to define how the Earth's magnetic field is disturbed under principally the effect of the Sun (Menvielle and Berthelier, 1991). These two parameters, $\mathrm{Kp}$ and $\mathrm{Sq}$ have the advantage to measure the state of the magnetic field at the Earth's surface and the upper atmosphere, respectively. This leads us to remote two key regions, the lithosphere where the EQ occurs and the atmosphere where electromagnetic precursor (like lithospheric electric field) are supposed to propagate before they reach the ionosphere.

\section{Conclusions}

Our investigations show a decrease of the VLF ionospheric emissions and transmitter signal preceding l'Aquila earthquake occurrence. The disturbance of both VLF radiations, several days before l'Aquila EQ, gives a clear evidence of the 
repeatability of this phenomena which has been reported by ground and space observations for other EQs. The reiteration of this phenomena provides a good opportunity to consider different physical aspects related, directly or indirectly, to the decrease of VLF intensity levels.

Acknowledgements. We acknowledge C. N. E. S. for the use of the DEMETER data, and thankful to Jean-Jacques Berthelier who provided us with data from the electric field experiment (Instrument Champ Électrique - ICE).

Edited by: M. E. Contadakis

Reviewed by: two anonymous referees

\section{References}

Berthelier, J. J., Godefroy, M., Leblanc, F., Malingre, M., Menvielle, M., Lagoutte, D., Brochot, J. Y., Colin, F., Elie, F., Legendre, C., Zamora, P., Benoist, D., Chapuis, Y., Artru, J., and Pfaff, R.: ICE, the electric field experiment on DEMETER, Planet. Space Sci., 54, 456-471, 2006.

Biagi, P. F. and Hayakawa, M.: Possible premonitory behaviour of LF radiowaves on the occasion of the Slovenia earthquakes (M=5.2-6.0-5.1) occurred on March-May 1998, in: Seismo-electromagnetics: Lithosphere-Atmosphere-Ionosphere Coupling, edited by: Hayakawa, M. and Molchanov, O., TERRAPUB, Tokyo, 249-253, 2002.

Biagi, P. F., Castellana, L., Maggipinto, T., Maggipinto, G., Minafra, A., Ermini, A., Capozzi, V., Perna, G., Solovieva, M., Rozhnoi, A., Molchanov, O. A., and Hayakawa, M.: Decrease in the electric intensity of $\mathrm{VLF} / \mathrm{LF}$ radio signals and possible connections, Nat. Hazards Earth Syst. Sci., 7, 423-430, doi:10.5194/nhess-7-423-2007, 2007.

Boudjada, M. Y., Schwingenschuh, K., Biernat, H. K., Berthelier, J. J., Blecki, J., Parrot, M., Stachel, M., Aydogar, Ö., Stangl, G., and Weingrill, J.: Similar behaviors of natural ELF/VLF ionospheric emissions and transmitter signals over seismic Adriatic regions, Nat. Hazards Earth Syst. Sci., 8, 1229-1236, doi:10.5194/nhess-8-1229-2008, 2008.

Denisenko, V. V., Boudjada, M. Y., Horn, M., Pomozov, E. V., Biernat, H. K., Schwingenschuh, K., Lammer, H., Prattes, G., and Cristea, E.: Ionospheric conductivity effects on electrostatic field penetration into the ionosphere, Nat. Hazards Earth Syst. Sci., 8, 1009-1017, doi:10.5194/nhess-8-1009-2008, 2008.

Gokhberg, M. B., Gufeld, I. L., Rozhnoi, A. A., Marenko, V. F., Yampolshy, V. S., and Ponomarev, E. A.: Study of seismic influence on the ionosphere by superlong wave probing of the Earthionosphere waveguide, Phys. Earth Planet. In., 57, 64-67, 1989.

Gokhberg, M. B., Pilipenko, V. A., and Pokhotelov, O. A.: Seismic precursors in the ionosphere, Izvestiya Russian Academy of Sciences, Physics of the Solid Earth, 19(10), 762-765, 1983.

Gokhberg, M. B., Morgunov, V. A., Yoshino, T., and Tomizawa, I.: Experimental measurement of electromagnetic emissions possibly related to earthquakes in Japan, J. Geophys. Res., 87, 78247828, 1982.

Gufeld, I. L., Rozhnoi, A. A., Tyumensev, S. N., Sherstuk, S. V., and Yampolsky, V. S.: Radiowave disturbances in period to Rudber and Rachinsk earthquakes, Phys. Solid Earth, 28(3), 267-270, 1992.
Hayakawa, M., Molchanov, O. A., Kodama, T., Afonin, V. V., and Akentieva, O. A.: Plasma density variations observed on a satellite possibly related to seismisity, Adv. Space Res., 26(8), 12771280, 2000.

Hayakawa, M., Molchanov, O. A., Ondoh, T., and Kawai, E.: The precursory signature effect of the Kobe earthquake on subionospheric VLF signals, J. Comm. Res. Lab., 43, 169-180, 1996 b.

Hayakawa, M. and Sato, H.: Ionospheric perturbations associated with earthquakes, as detected by subionospheric VLF propagation, in: Electromagnetic Phenomena Related to Earthquake Prediction, edited by: Hayakawa, M. and Fujinawa, Y., TERRAPUB, Tokyo, 391-397, 1994.

Hobara, Y., Lefeuvre, F., Parrot, M., and Molchanov, O. A.: Lowlatitude ionospheric turbulence observed by Aureol-3 satellite, Ann. Geophys., 23, 1259-1270, doi:10.5194/angeo-23-12592005, 2005.

Lagoutte, D., Brochot, J. Y., de Carvalho, D., Elie, F., Harivelo, F., Hobara, Y., Madrias, L., Parrot, M., Pinc-on, J. L., Berthelier, J. J., Peschard, D., Seran, E., Gangloff, M., Sauvaud, J. A., Lebreton, J. P., Stverak, S., Travnicek, P., Grygorczuk, J., Slominski, J., Wronowski, R., Barbier, S., Bernard, P., Gaboriaud, A., and Wallut, J. M.: The DEMETER science mission centre, Planet. Space Sci., 54, 428-440, 2006.

Liu, J. Y., Chuo, Y. J., and Chen, Y. I.: Ionospheric GPS TEC perturbations prior to the 20 September 1999, Chi-Chi earthquake, Geophys. Res. Lett., 28, 1383-1386, 2001.

Menvielle, M. and Berthelier, J. J.: The K-derived planetary indices - Description and availability, Rev. Geophys., 29, 415-432, 1991.

Molchanov O. and Hayakawa, M.: Seismo-electromagnetics and related phenomena: History and latest results, TERRAPUB, Tokyo, 2008.

Molchanov, O., Rozhnoi, A., Solovieva, M., Akentieva, O., Berthelier, J. J., Parrot, M., Lefeuvre, F., Biagi, P. F., Castellana, L., and Hayakawa, M.: Global diagnostics of the ionospheric perturbations related to the seismic activity using the VLF radio signals collected on the DEMETER satellite, Nat. Hazards Earth Syst Sci., 6, 745-753, doi:10.5194/nhess-6-745-2006, 2006.

Molchanov, O. A., Akentieva, O. S., Afonin, V. V., Mareev, E. A., and Fedorov, E. N.: Plasma density-electric field turbulence in the low-latitude ionosphere from the observation on satellites; possible connection with seismicity, Phys. Chem. Earth, 29, 569577, 2004.

Molchanov, O. A. and Hayakawa, M.: Subionospheric VLF signal perturbations possibly related to earthquakes, J. Geophys. Res., 103, 17489-17504, 1998.

Muto, F., Yoshida, M., Horie, T., Hayakawa, M., Parrot, M., and Molchanov, O. A.: Detection of ionospheric perturbations associated with Japanese earthquakes on the basis of reception of LF transmitter signals on the satellite DEMETER, Nat. Hazards Earth Syst. Sci., 8, 135-141, doi:10.5194/nhess-8-135-2008, 2008.

Němec, F., Santolík, O., and Parrot, M.: Decrease of intensity of ELF/VLF waves observed in the upper ionosphere close to earthquakes: a statistical study, J. Geophys. Res., 114, A04303, doi:10.1029/2008JA013972, 2009.

Parrot, M., Benoist, D., Berthelier, J. J., Blecki, J., Chapuis, Y., Colin, F., Elie, F., Fergeau, P., Lagoutte, D., Lefeuvre, F., Legendre, C., Leveque, M., Pincon, J. L., Poirier, B., Serana, H. C., and 
Zamora, P.: The magnetic field experiment IMSC and its data processing onboard DEMETER: Scientific objectives, description and first results, Planet. Space Sci., 54, 441-455, 2006a.

Parrot, M., Berthelier, J. J., Lebreton, J. P., Sauvaud, J. A., Santolík, O., and Blecki, J.: Examples of unusual ionospheric observations made by the DEMETER satellite over seismic regions, Phys. Chem. Earth, 31, 486-495, 2006 b.

Parrot, M., Achache, J., Berthelier, J. J., Blanc, E., Deschamps, A., Lefeuvre, F., Menvielle, M., Planet, J. L., Tarits, P., and Villain, J. P.: High-frequency seismo-electromagnetic effects, Phys. Earth Planet. In., 77, 65-83, 1993.

Pulinets, S. A. and Boyarchuk, K. A.: Ionospheric Precursors of Earthquakes, Springer, New York, 2004.

Pulinets, S. A., Hegai, V. V., Kim, V. P., and Depuev, V. K.: Unusual longitude modification of the night-time mid-latitude $\mathrm{F} 2$ region ionosphere in July 1980 over the array of tectonic faults in the Andes area: observations and interpretation, Geophys. Res. Lett., 25, 4133-4136, 1998.

Pulinets, S. A., Legen'ka, A. D., and Alekeseev, V. A.: Preearthquake ionospheric effects and their possible mechanisms, in Dusty and Dirty Plasmas, Noise and Chaos in Spac and in Laboratory, Plenum Publishing, New York, 545-557, 1994.
Rozhnoi, A., Solovieva, M., Molchanov, O., Schwingenschuh, K., Boudjada, M., Biagi, P. F., Maggipinto, T., Castellana, L., Ermini, A., and Hayakawa, M.: Anomalies in VLF radio signals prior the Abruzzo earthquake $(M=6.3)$ on 6 April 2009, Nat. Hazards Earth Syst. Sci., 9, 1727-1732, doi:10.5194/nhess-91727-2009, 2009

Rozhnoi, A., Molchanov, O., Solovieva, M., Gladyshev, V., Akentieva, O., Berthelier, J. J., Parrot, M., Lefeuvre, F., Hayakawa, M., Castellana, L., and Biagi, P. F.: Possible seismo-ionosphere perturbations revealed by VLF signals collected on ground and on a satellite, Nat. Hazards Earth Syst. Sci., 7, 617-624, doi:10.5194/nhess-7-617-2007, 2007.

Rozhnoi, A., Solovieva, M. S., Molchanov, O. A., and Hayakawa, M.: Middle latitude $\mathrm{LF}(40 \mathrm{kHz})$ phase variations associated with earthquakes for quiet and disturbed geomagnetic conditions, Phys. Chem. Earth, 29, 589-598, 2004.

Warwick, J. W., Stoker, C., and Meyer, T. R.: Radio emission associated with rock fracture: possible application to the great Chilean earthquake of May 22, 1960, J. Geophys. Res., 87, 2851-2859, 1982.

Yamauchi, T., Maekawa, S., Horie, T., Hayakawa, M., and Soloviev, O.: Subionospheric VLF/LF monitoring of ionospheric perturbations for the 2004 Mid-Niigata earthquake and their structure and dynamics, J. Atmos. Sol.-Terr. Phys., 69, 793-802, 2007. 